\title{
A Mass Spectrometry Study of Tirapazamine and Its Metabolites: Insights Into the Mechanism of Metabolic Transformations and the Characterization of Reaction Intermediates
}

\author{
Dmitri Zagorevskii, Minghu Song, and Curt Breneman \\ Department of Chemistry, Rensselaer Polytechnic Institute, Troy, New York, USA \\ Yang Yuan, Tarra Fuchs, Kent S. Gates, and C. Michael Greenlief \\ Department of Chemistry, University of Missouri-Columbia, Columbia, Missouri, USA
}

\begin{abstract}
Tandem mass spectrometry methods were used to study the sites of protonation and for identification of 3-amino-1,2,4-benzotriazine 1,4-dioxide (1, tirapazamine), and its metabolites (3-amino-1,2,4-benzotriazine 1-oxide (3), 3-amino-1,2,4-benzotriazine 4-oxide (4), 3-amino1,2,4-benzotriazine (5), and a related isomer 3-amino-1,2,4-benzotriazine 2-oxide (6). Fragmentation pathways of $\mathbf{3}$ and $\mathbf{5}$ indicated the $4-\mathrm{N}$-atom as the most likely site of protonation. Among the N-oxides studied, the 4-oxide (4) showed the highest degree of protonation at the oxygen atom. The differences in collision-induced dissociation of isomeric protonated 1-, 2and 4-oxides allowed for their identification by LC/MS/MS. Gas phase and liquid phase protonation of tirapazamine occurred exclusively at the oxygen in the 4-position. A loss of $\mathrm{OH}$ radical from these ions $\left(2^{+}\right)$resulted in ionized 3 . Neutralization-reionization mass spectrometry (NR MS) experiments demonstrated the stability of the neutral analogue of protonated tirapazamine in the gas phase in the $\mu$ s time-frame. A significant portion of the neutral tirapazamine radicals (2) dissociated by loss of hydroxyl radical during the NR MS event, which indicates that previously proposed mechanisms for redox-activated DNA damage are reasonable. The activation energy for loss of hydroxyl radical from activated tirapazamine (2) was estimated to be $\sim 14 \mathrm{kcal} \mathrm{mol}^{-1}$. Stable neutral analogues of $[3+\mathrm{H}]^{+}$and $[5+\mathrm{H}]^{+}$ions were also generated in the course of NR MS experiments. Structures of these radicals were assigned to the molecules having an extra hydrogen atom at one of the ring $\mathrm{N}$-atoms. Quantum chemical calculations of protonated 1, 3, 4 and 5 and the corresponding neutrals were performed to assist in the interpretation of experimental results and to help identify their structures. (J Am Soc Mass Spectrom 2003, 14, 881-892) @ 2003 American Society for Mass Spectrometry
\end{abstract}

$\mathrm{T}$ irapazamine (1; 3-Amino-1,2,4-benzotriazine 1,4dioxide, SR 4233) is a promising new antitumor agent that selectively damages DNA in oxygenpoor (hypoxic) tumour cells [1, 2]. In the cell, this drug undergoes one-electron enzymatic reduction to yield radical-anion $\mathbf{1}^{-}$. This species has previously been generated in aqueous solution by pulse radiolysis and its lifetime and $\mathrm{pK}_{\mathrm{b}}$ determined using UV-vis spectroscopy [3-5]. It is known that under low-oxygen conditions, the activated drug causes cytotoxic damage [6-11]. The exact mechanism by which DNA damage

Published online June 18, 2003

Address reprint requests to Dr. D. V. Zagorevskii, Department of Chemistry, Rensselaer Polytechnic Institute, 110 8th St., Troy, NY 12180, USA. E-mail: zagord@rpi.edu occurs remains uncertain. Recent studies have provided support for the idea that neutral radical 2 undergoes homolytic fragmentation to produce the well known DNA-damaging agent hydroxyl radical, $\mathrm{OH}$, and the observed mono-N-oxide metabolite 3 [6] (Scheme 1). Although this mechanism is widely accepted at this time, no direct experimental evidence exists to support the formation of the radical 2 .

In the present paper, we report the results of several mass spectroscopic studies related to the drug tirapazamine. Neutralization-reionization mass spectrometry (NR MS) [12, 13] was used to generate the biologically relevant intermediate 2 in the gas phase in its pure form and provide the first direct evidence that the loss of hydroxyl radical from this species is energetically reasonable. In addition, we have developed an 


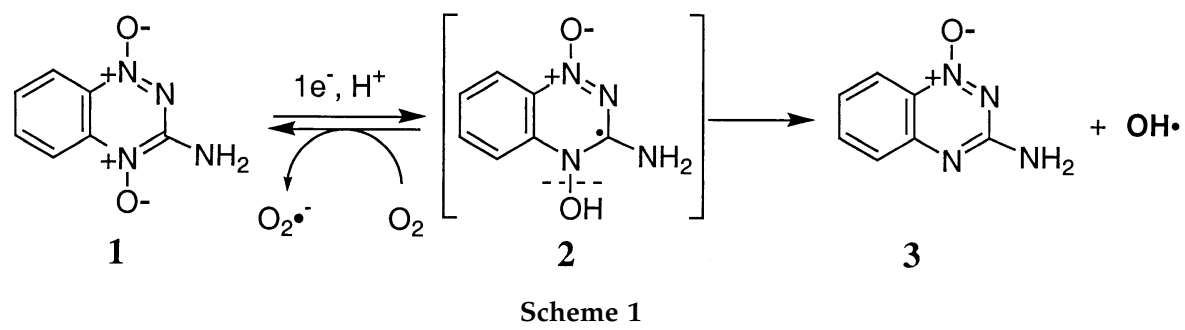

LC/MS/MS method employing selective reaction monitoring for the unambiguous detection of tirapazamine and its known metabolites (3, 4, and 5). Finally, a variety of ionization techniques were used to generate protonated 1, 3-5 and another monoxide, $\mathbf{6}$. Tandem mass spectrometry methods combined with quantum chemical calculations were applied to determine sites of protonation of these molecules. The results of this work provide practical tools for the analysis of mixtures containing tirapazamine and its metabolites and also offer some important fundamental insights regarding the reactivity of this interesting drug.<smiles>Nc1nnc2ccccc2n1</smiles>

\section{Experimental}

Compounds 1 and 3-6 were synthesized according to literature procedures [14]. Their identity and purity were confirmed by ${ }^{1} \mathrm{H}$ - and ${ }^{13} \mathrm{C}-\mathrm{NMR}$, HPLC, and LC/MS methods.

Electron ionization (EI) mass spectra were recorded using a ThermoFinnigan TSQ7000 (San Jose, CA) and a modified VG Analytical ZAB-2E (BEB configuration) mass spectrometer (Manchester, UK). Energy of ionizing electrons was $70 \mathrm{eV}$ and the ion source temperature was $200-250^{\circ} \mathrm{C}$. All compounds were introduced to the ion source using direct insertion probes. Moderate evaporation temperatures $\left(100-175^{\circ} \mathrm{C}\right)$ were employed in order to avoid thermal decomposition of the compounds.

Accurate mass measurements in EI mode were performed on a VG Analytical 7070 (EB configuration) mass spectrometer by peak matching technique using perfluorokerosene as an internal standard. Resolving powers were 5000-9000 and the accuracy of mass measurements was better than $0.0030 \mathrm{Da}$. The compounds were introduced into the ion source using a heated direct inlet probe.

Chemical ionization (CI) mass spectra were obtained using both the TSQ7000 and ZAB-SE instruments. The ion source temperatures were maintained at $100{ }^{\circ} \mathrm{C}$ and the filament currents were $20 \mu \mathrm{A}$. When isobutane was used as a reagent gas, the formation $[\mathrm{MH}]^{+}$ions was accompanied by the generation of a significant amount of molecular ions. The latter were the result of charge exchange reactions between neutral molecules of analytes and reactant ions. For this reason ammonia chemical ionization mass spectra were recorded. The $\left[\mathrm{M}^{+\cdot}\right] /$ $[\mathrm{MH}]^{+}$ion intensity ratios in the $\mathrm{CI}\left(\mathrm{NH}_{3}\right)$ mass spectra of Compounds $\mathbf{1}$ and 3-6 were less than 8\%, implying that the contribution of isotopic peaks of molecular ions to the intensity of $[\mathrm{MH}]^{+}$did not exceed $\sim 1 \%$ of the latter.

Direct infusion electrospray ionization (ESI) experiments were performed on the TSQ7000 triple-stage quadrupole mass spectrometer. All compounds were injected in methanol/water or acetonitrile/water solutions using a syringe pump at flow rate of $\sim 10 \mu \mathrm{L} / \mathrm{min}$. Positive ion ESI mass spectra were obtained at spray voltages of $4-4.5 \mathrm{kV}$. The heated capillary temperature was $200-300{ }^{\circ} \mathrm{C}$. In atmospheric pressure chemical ionization (APCI) experiments, samples were injected into the solvent flow at a rate of $200 \mu \mathrm{L} / \mathrm{min}$. The evaporator temperature was $500{ }^{\circ} \mathrm{C}$ and the heated capillary temperature was $175^{\circ} \mathrm{C}$ for the APCI experiments.

Collision-induced dissociation (CID) mass spectra were obtained on the ZAB-SE (translational energy of ions $8 \mathrm{kV}$ ) and TSQ7000 (laboratory collision energy $10-35 \mathrm{eV}$ ) mass spectrometers using oxygen and argon as collision gases, respectively.

Neutralization-reionization mass spectra were recorded on the ZAB-SE mass spectrometer using a MTI MS/MS data acquisition and data processing system (Mommers Technologies, Inc., Vanier, Ontario, Canada). Nitric oxide was used for neutralization $(80 \%$ main ion beam transmission) and oxygen for reionization (70\% main ion beam transmission). A potential of 1000 $\mathrm{V}$ was applied to the deflector electrode to remove all ions leaving the first collision cell from the beam of fast moving neutrals. Lifetimes of neutrals in NR MS experiments were calculated using a simple equation including the accelerating voltage of $8000 \mathrm{~V}$ and the distance between the two collision cells, $\sim 5 \mathrm{~cm}$. Depending on the mass-to-charge ratio of the neutralized ions, the calculated lifetimes were $\sim 4-5 \mu \mathrm{s}$.

LC/MS and LC/MS/MS analyses were performed on the TSQ7000 triple-stage quadrupole mass spectrometer coupled with a ThermoSeparation Products 4000 HPLC system and operated by Xcalibur software. A 
Table 1. Electron ionization $(70 \mathrm{eV})$ mass spectra of $\mathbf{1}$ and 3-6 (Intensities are in percent to the base peak)

\begin{tabular}{rccccc}
\hline$m / z$ & $\mathbf{1}$ & $\mathbf{3}$ & $\mathbf{4}$ & $\mathbf{6}$ & $\mathbf{5}$ \\
\hline \hline 178 & 100 & - & - & - & - \\
162 & 45 & 100 & 100 & 91 & - \\
146 & 1 & - & - & - & 51 \\
145 & - & - & 1 & 20 & - \\
136 & 38 & - & - & - & - \\
134 & - & - & 2 & - & - \\
132 & - & - & - & 100 & - \\
118 & 6 & 14 & 9 & 11 & 100 \\
117 & 3 & 5 & 13 & 18 & - \\
116 & 1 & - & 17 & - & - \\
105 & 2 & 3 & 7 & 55 & - \\
91 & 11 & 25 & 7 & 12 & 36 \\
90 & 9 & 17 & 29 & 22 & 7 \\
76 & 8 & 7 & 7 & 5 & 8 \\
64 & 4 & 16 & 10 & 6 & 6 \\
63 & 1 & 9 & 11 & 7 & 5 \\
50 & 1 & 8 & 10 & 8 & 10 \\
\hline
\end{tabular}

50:50 mixture of water and acetonitrile containing $0.1 \%$ of formic acid or 10:20:70 mixture of acetonitrile, methanol and water were used as isocratic mobile phases. The typical flow rate was $0.8 \mathrm{~mL} / \mathrm{min}$. A C-18 reverse phase Rainin Microsorb-MV column (4.6 mm i.d., $100 \AA$ sphere size, $5 \mathrm{~mm}$ pore size, $25 \mathrm{~cm}$ length) was used for separation.

Quantum chemical calculations were carried out by the GAUSSIAN 98 program [15]. The structures of neutral and charged species were optimized with the B3LYP hybrid density functional [16] in conjunction with the $6-31 G^{*}$ basis set. The B3LYP functional is the combination of Becke's three-parameter hybrid exchange functional and the Lee-Yang-Par correlation relation function [17]. Relative energies were obtained by performing single-point energy calculations at the same level of theory and basis set using the aboveoptimized geometries. The obtained harmonic vibration frequencies at the same level were used to calculate the zero-point energy corrections (ZPE). For open shell systems, such as $[\mathrm{M}+\mathrm{H}]$ radicals, two procedures were employed. In the first method, the precalculated geometry of a neutral molecule was used and a hydrogen atom was added to a heavy atom. In the other method, unrestricted optimization (UB3LYP) of radical geometry was performed.

\section{Results and Discussion}

\section{EI and CID Mass spectra of Ionized 1 and 3-6}

Electron impact mass spectra of tirapazamine, its metabolites, and 2-oxide, 6, are listed in Table 1. All compounds produced strong molecular ion signals. Fragmentation pathways of $\mathrm{M}^{+\cdot}$ ions and their relationship to compound structure are discussed below. Partial EI mass spectra have been previously published [14] for $\mathbf{1}$ and 3-4 and are qualitatively similar to the data shown in Table 1.
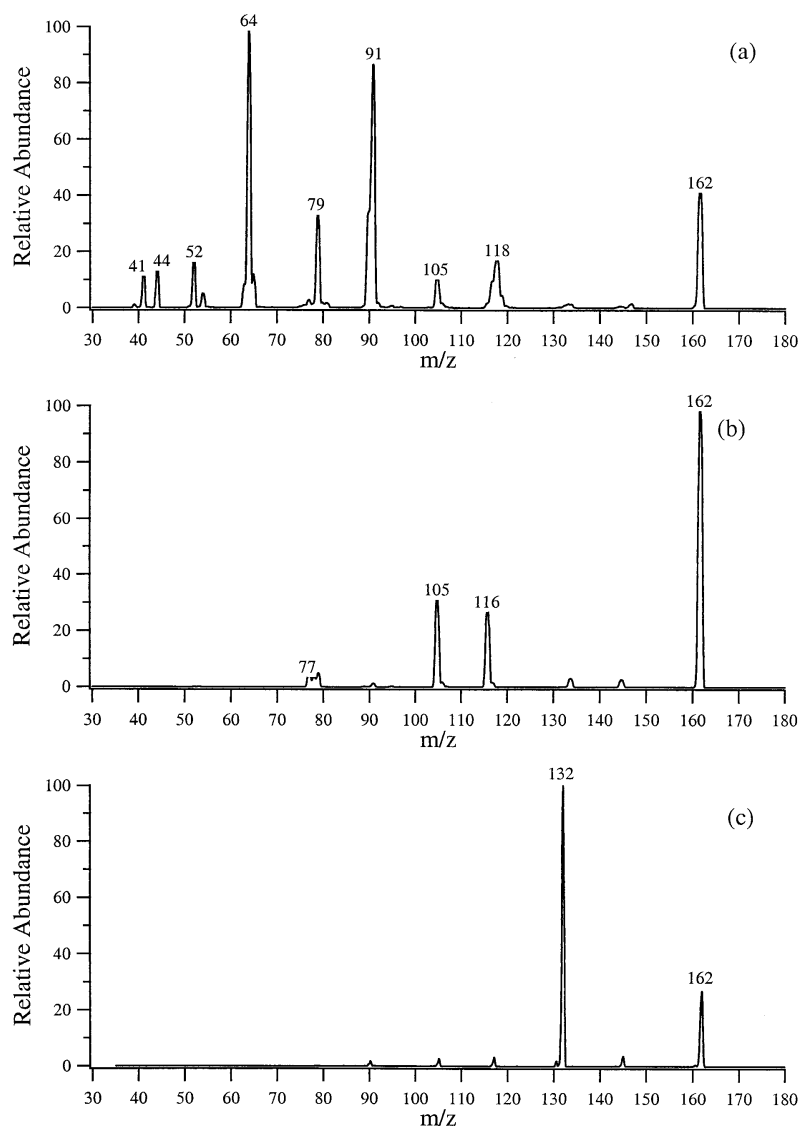

Figure 1. CID mass spectra of 3-amino-1,2,4-benzotriazine 1-oxide, 3 (a), 4-oxide, 4 (b), and 2-oxide, 6 (c).

The EI mass spectrum of 3-amino-1,2,4-benzotriazine, 5, displayed a strong molecular ion peak at $\mathrm{m} / \mathrm{z}$ 146. The most abundant dissociation product corresponded to the loss of $\mathrm{N}_{2}(\mathrm{~m} / \mathrm{z} 118)$. Further fragmentation of $\left[\mathrm{M}-\mathrm{N}_{2}\right]^{+\cdot}$ ions gave rise to all other fragments, as verified by MS/MS experiments. Peaks in the lowmass region appeared at $\mathrm{m} / \mathrm{z} 91$ and 76 , and corresponded to losses of $\mathrm{HCN}$ (or $\mathrm{CNH}$ ) and $\mathrm{NCNH}_{2}$ from the $\left[\mathrm{M}-\mathrm{N}_{2}\right]^{+\cdot}$ ion. CID mass spectra of mass-selected molecular ions of 5 were obtained in low- and highenergy collision regimes (not shown) and were similar to the EI mass spectrum. In all cases, $\left[\mathrm{M}-\mathrm{N}_{2}\right]^{+\cdot}$ ions and their dissociation products dominated the fragmentation.

The EI mass spectrum of 3-amino-1,2,4-benzotriazine 1-oxide, 3, showed the molecular ion peak at $m / z 162$ as the base peak. Major fragment ions were similar to the EI mass spectrum of 5 . The highest mass fragment ion at $\mathrm{m} / \mathrm{z} 118$ corresponded to a loss of $\mathrm{N}_{2} \mathrm{O}$. This was determined by accurate mass measurements (calculated mass for $\mathrm{C}_{7} \mathrm{H}_{6} \mathrm{~N}_{2}$ 118.0531, measured mass 118.0524; all other atomic combinations that could be composed from 3 have significantly lower masses). A single-step elimination of $\mathrm{N}_{2} \mathrm{O}$ from $3^{+\cdot}$ ions was confirmed by the CID mass spectrum of the molecular ions (Figure 1a), which resembled the EI mass spectrum. Formation of 
ions at $m / z 105$ must have taken place directly from the molecular ions of 3 , because they were not observed in the EI mass spectrum of 5 . Accurate mass measurements for ions at $\mathrm{m} / \mathrm{z} 105$ (105.0420) in the EI mass spectrum of 3 were consistent with the composition $\mathrm{C}_{6} \mathrm{H}_{5} \mathrm{~N}_{2}$ (calc.105.0453), implying that $\mathrm{CHN}_{2} \mathrm{O}$ was lost as a neutral. However, structures of the ion and neutral remain unclear.

The molecular ion peak was abundant in the EI mass spectrum of $\mathbf{6}$. A peak at $\mathrm{m} / \mathrm{z} 118$ corresponded to a loss of $\mathrm{N}_{2} \mathrm{O}$ and was consistent with the presence of an oxygen atom at the $\mathrm{N}=\mathrm{N}$ group. Peaks due to [M $\mathrm{OH}^{+}{ }^{+}\left(m / z\right.$ 145) and $\left[\mathrm{M}-\mathrm{NO}^{+}\right]^{+}(m / z$ 132) ions were the characteristic that differed from the EI mass spectra of isomeric 3 and 6 (Table 1) and the CID mass spectra (Figure 1) of their molecular ions. The loss of $\mathrm{HO}^{-}$was consistent with the presence of a neighboring aminogroup to the oxygen atom. This proximal relationship resulted in a hydrogen atom transfer between the two heteroatoms. A loss of $\mathrm{NO}^{\circ}$ is a unique feature of ionized 6. This reaction is very uncharacteristic for heterocyclic N-oxides [18, 19], including Compounds $\mathbf{1}$, 3 and 4 . The stability of the reaction products, 7 and $\mathrm{NO}$, may be the reason for this unusual reaction.

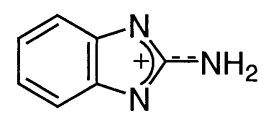

7

The EI mass spectrum of 4 was dominated by the molecular ion. A minor peak, corresponding to a loss of $\mathrm{HO}$, indicated a hydrogen atom migration between the amino group and the oxygen atom. There were some differences in the fragmentation of the ionized 4 and its isomers, 1-N- (3) and 2-N-oxides (6). A loss of $\mathrm{N}_{2}$ was a unique feature of the ionized 4 . Unlike 3 and 6,4 has no oxygen atom attached to the $\mathrm{N}=\mathrm{N}$ group of the heterocycle. As a result, a small peak at $\mathrm{m} / \mathrm{z} 118$ was detected in EI mass spectra (Table 1$)$ and the peak $(\mathrm{m} / \mathrm{z} 118)$ was absent in CID mass spectra of $\mathbf{4}^{+\cdot}$ (Figure 1). Instead, a direct elimination of $\mathrm{N}_{2}$ was observed. A loss of $\mathrm{N}_{2}$ also occurred from $[\mathrm{M}-\mathrm{OH}]^{+}$ions. The presence of a strong peak at $m / z 116$ in both the EI and CID mass spectra of 4 indicates the loss of $\mathrm{H}_{2} \mathrm{O}$ from $\left[\mathrm{M}-\mathrm{N}_{2}\right]^{+\cdot}$.

Comparison of the behavior of isomeric 3-amino1,2,4-benzotriazine monoxides 3, 4, and 6 revealed some similarities in their fragmentation, along with isomerspecific dissociations. Only molecular ions of ionized 2-oxide showed a loss of NO. The proximity of oxygen atoms to the amino group is the rationale for the losses of $\mathrm{OH}^{\circ}$ from the molecular ions of 2-oxide and 4-oxide. Molecular ions of 4-oxide did not lose $\mathrm{N}_{2} \mathrm{O}$, which was characteristic for the isomers having an oxygen atom attached to the $\mathrm{N}=\mathrm{N}$ group. The absence of oxygen atom at $1-\mathrm{N}$ or $2-\mathrm{N}$ atoms, e.g., in Compound 4, is consistent with the observation of $\mathrm{N}_{2}$ loss directly from the mo-

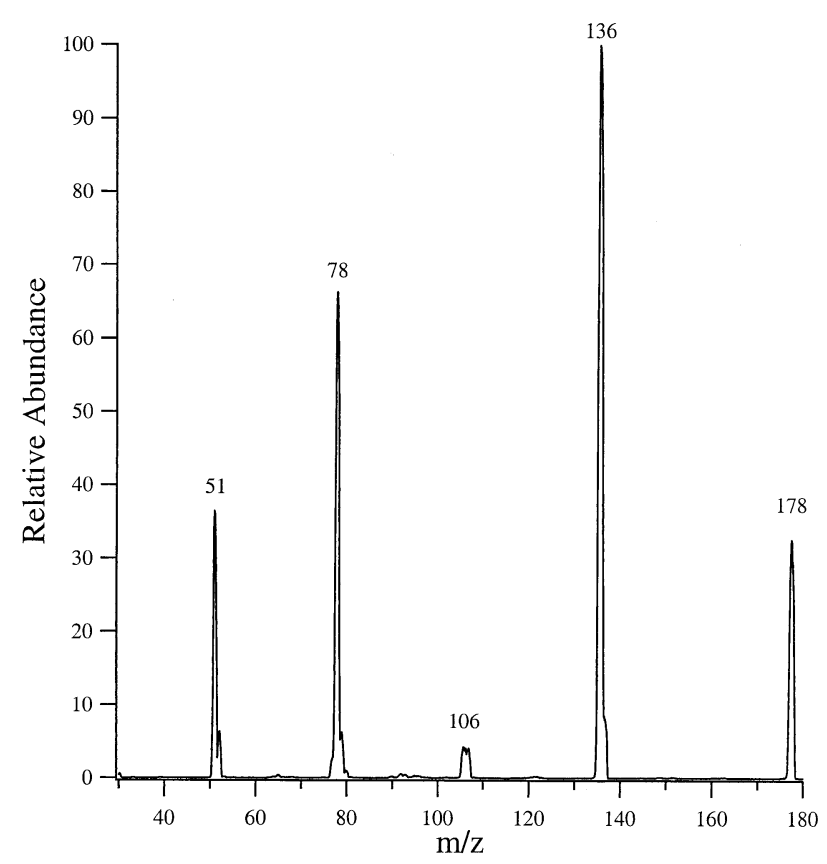

Figure 2. CID mass spectrum for the radical cation of 3-amino1,2,4-benzotriazine 1,4-dioxide, 1.

lecular ions. A similar process produced $\left[\mathrm{M}-\mathrm{N}_{2}\right]^{+\cdot}$ as a major fragmentation ion of ionized 5 . EI and CID mass spectra of monoxides 3, 4, and 6 can be used for the identification of these compounds.

The EI mass spectrum of I showed a very strong signal for molecular ions. The presence of a peak at $\mathrm{m} / \mathrm{z}$ 162 was a likely result of thermal decomposition of $\mathbf{1}$ in the heated direct probe or in the ion source of the mass spectrometer. The CID mass spectrum of ions at $m / z 162$ was consistent with the formation of 1-oxide, 3 . Because of an inability to differentiate EI-induced dissociations of $\mathbf{1}$ and $\mathbf{3}$ (due to thermal conversion of one to the other), the CID mass spectrum of mass-selected ions at $\mathrm{m} / \mathrm{z} 178$ (Figure 2) was recorded to identify fragmentation pathways that are characteristic for ionized 1 . The dissociation of $\mathbf{1}^{+\cdot}$ ions was dominated by a retro-DielsAlder reaction, involving a loss of neutral cyanamide, $\mathrm{NCNH}_{2}$. The resulting ions, $\left[1-\mathrm{NCNH}_{2}\right]^{+\cdot}$, most likely possessed the structure of the ionized 1,2-dinitrosobenzene. Subsequent dissociation resulted in a loss of NO followed by elimination of other small molecules (CO and $\mathrm{C}_{2} \mathrm{H}_{2}$ ).

\section{CID of Protonated 3-Amino-1,2,4-Benzotriazine Monoxides}

Compounds $\mathbf{1}$ and 3-6 produced abundant protonated ions under CI, ESI and APCI conditions. While signal intensities in the CID mass spectra were dependant on instrumental conditions, such as collision energy, the dissociation characteristics of ions of the same compound were indistinguishable regardless of the ionization technique used. For this reason, the ionization method may not be specified throughout the remainder 

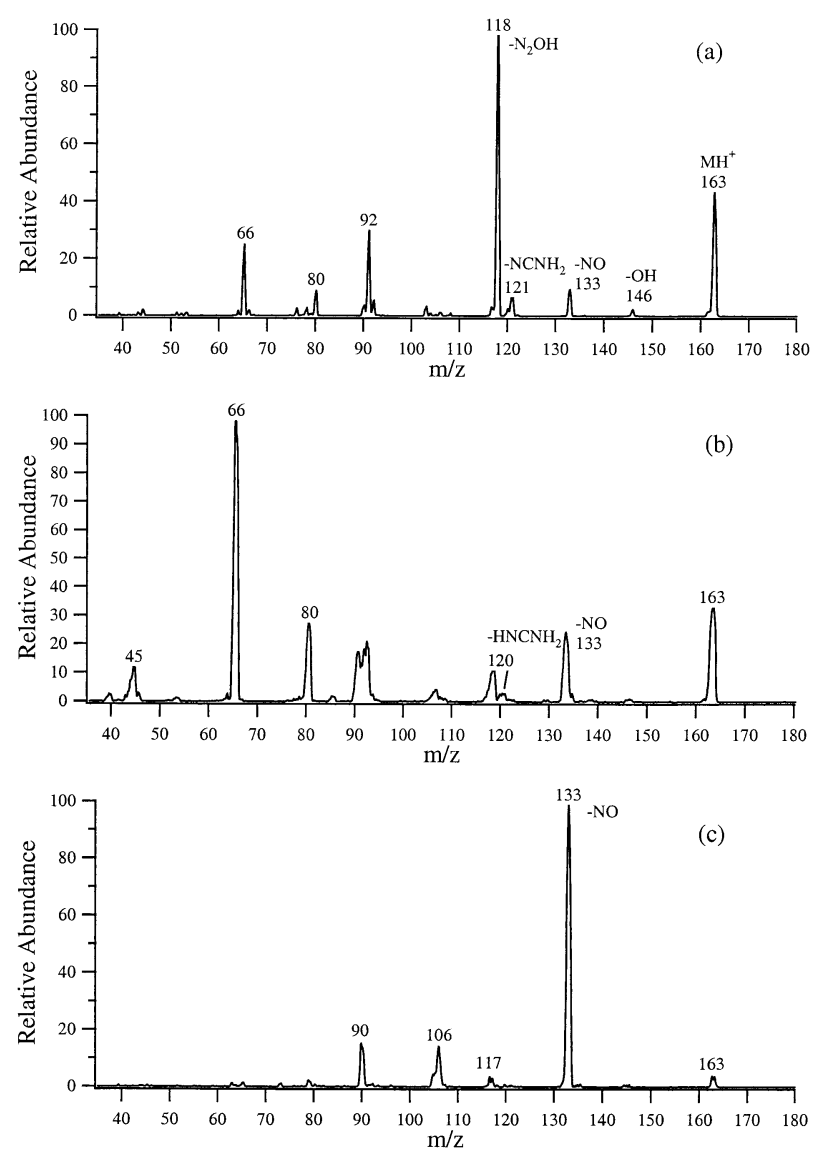

Figure 3. CID mass spectra of protonated 3-amino-1,2,4-benzotriazine 1-oxide, 3 (a), 4-oxide, 4 (b), and 2-oxide, 6 (c).

of the discussion, unless differences in the behavior of the ions merit doing so. Similarities in the behavior of $[\mathrm{MH}]^{+}$ions generated by protonation of neutral molecules by various techniques such as classical CI, APCI or ESI implies that protonation occurs at the same site (or sites) on a given molecule and the internal energy distributions of the resulting ion populations are similar, and is thereby independent of the ionization method used to achieve protonation.

CID mass spectra of protonated isomeric monoxides obtained on the triple-quadrupole instrument are shown in Figure 3. Many common fragment ions were observed for the fragmentation of $[3+\mathrm{H}]^{+},[4+\mathrm{H}]^{+}$ and $[6+\mathrm{H}]^{+}$ions. Each ion showed some characteristic dissociation pathways.

A common fragmentation pathway of protonated 3, 4 , and 6 was a loss of NO. The loss of nitric oxide was particularly pronounced from protonated 6 . This reaction was the only dissociation product of metastable $[6+\mathrm{H}]^{+}$ions. It was also observed that the CID mass spectra of the ionized, $5^{+\cdot}$, and deprotonated 3-amino1,2,4-benzotriazine 2-oxide, $[6-\mathrm{H}]^{-}$, also displayed signals due to loss of $\mathrm{NO}$.

The CID mass spectra of $[3+\mathrm{H}]^{+}$and $[4+\mathrm{H}]^{+}$ions were significantly different from the CID mass spectrum of the protonated 6 (Figure 3). Peaks are observed at $m / z 118,92,91$, and 66 . These peaks were negligible in the CID mass spectrum of $[6+\mathrm{H}]^{+}$. The $m / z 92$ and 91 ions can be attributed to consecutive losses of $\mathrm{N}_{2} \mathrm{OH}$ and $\mathrm{C}_{2} \mathrm{H}_{2}$ or $\mathrm{N}_{2} \mathrm{OH}$ and $\mathrm{HCN}$. The relative contributions of $\left[\mathrm{M}+\mathrm{H}-\mathrm{HON}_{2}\right]^{+}$ions, corresponding to a mass difference of 45 , to the fragmentation pattern of $[3+\mathrm{H}]^{+}$was significantly higher than what was observed for the fragmentation pattern of $[4+\mathrm{H}]^{+}$at any fixed collision energy. This observation can be rationalized by the different structures of 3 and 4 . For Structure 3 , the oxygen atom is directly attached to the diazo-fragment. This arrangement makes it possible to eliminate $\mathrm{N}_{2} \mathrm{OH}$ as a whole unit ( $\mathrm{NNOH}$ or $\mathrm{HNNO}$ ). In 4, $\left[\mathrm{MH}-\mathrm{HON}{ }_{2}\right]^{+\cdot}$ can only be formed by consecutive losses of $\mathrm{OH}^{-}$and $\mathrm{N}_{2}$. It is possible that $[\mathrm{M}+\mathrm{H}-$ $\left.\mathrm{HON}_{2}\right]^{+}$ions formed from protonated 3 could possess higher internal energies and dissociate more extensively than ions generated from $[4+\mathrm{H}]^{+}$. It should be noted, however, that the loss of $\mathrm{HON}_{2}$ from $[3+\mathrm{H}]^{+}$ could not be confirmed directly. The NR mass spectrum of $[3+\mathrm{H}]^{+}$did not display a peak at $m / z 45$, which would correspond to stable reionized $\mathrm{N}_{2} \mathrm{OH}$.

The stepwise elimination of $\mathrm{OH}$ and $\mathrm{N}_{2}$ from protonated 4-oxide was confirmed by the presence of a peak at $m / z 146$ in the CID mass spectrum of $[4+\mathrm{H}]^{+}$. Additional collisional excitation of in-source generated mass-selected $[\mathrm{MH}-\mathrm{OH}]^{+\cdot}$ ions resulted in extensive loss of $\mathrm{N}_{2}$. The CID mass spectrum of these ions was indistinguishable from the CID mass spectrum of the ionized 5, indicating that the loss of $\mathrm{OH}^{-}$from $[4+\mathrm{H}]^{+}$ resulted in ionized 3-amino-1,2,4-benzotriazine.

Other differences between $[3+\mathrm{H}]^{+}$and $[4+\mathrm{H}]^{+}$ ions were associated with a retro-Diels-Alder like dissociation. A loss of $\mathrm{NCNH}_{2}$ was observed for protonated 1 -oxide giving rise to ions at $m / z 121$. A similar process was detected for $[4+\mathrm{H}]^{+}$that resulted in ions at $\mathrm{m} / \mathrm{z}$ 120; their formation may be explained by a loss of a radical (empirical formula, $\mathrm{CH}_{3} \mathrm{~N}_{2}$ ). [3 $3+\mathrm{H}-$ $\left.\mathrm{NCNH}_{2}\right]^{+}$and $\left[4+\mathrm{H}-\mathrm{NCNH}_{3}\right]^{+\cdot}$ were minor products of dissociation for protonated 3 and 4 . Nevertheless, the presence or absence of these ions is used for the identification of the isomers.

The differences in the unimolecular dissociation of isomeric 3-amino-1,2,4-benzotriazine monoxides were used to help identify these compounds in complex mixtures using LC/MS and LC/MS/MS techniques. Two isocratic mobile phases were used for separation of mixtures of tirapazamine and its metabolites. The retention times were generally shorter when water/acetonitrile (50:50) containing $0.1 \%$ formic acid was used as the mobile phase, compared to the mobile phase containing methanol, acetonitrile, and water (20:10:70). With either mobile phase, the compounds of interest were easily ionized, yielding $[\mathrm{MH}]^{+}$ions. The presence of acetonitrile in both mobile phases gave rise to solvates, $\left[\mathrm{M} . . \mathrm{H}^{+} \ldots \mathrm{NCCH}_{3}\right]$. Their observation confirmed the presence of the corresponding molecules. However, if quantitative LC/MS measurements are to be per- 

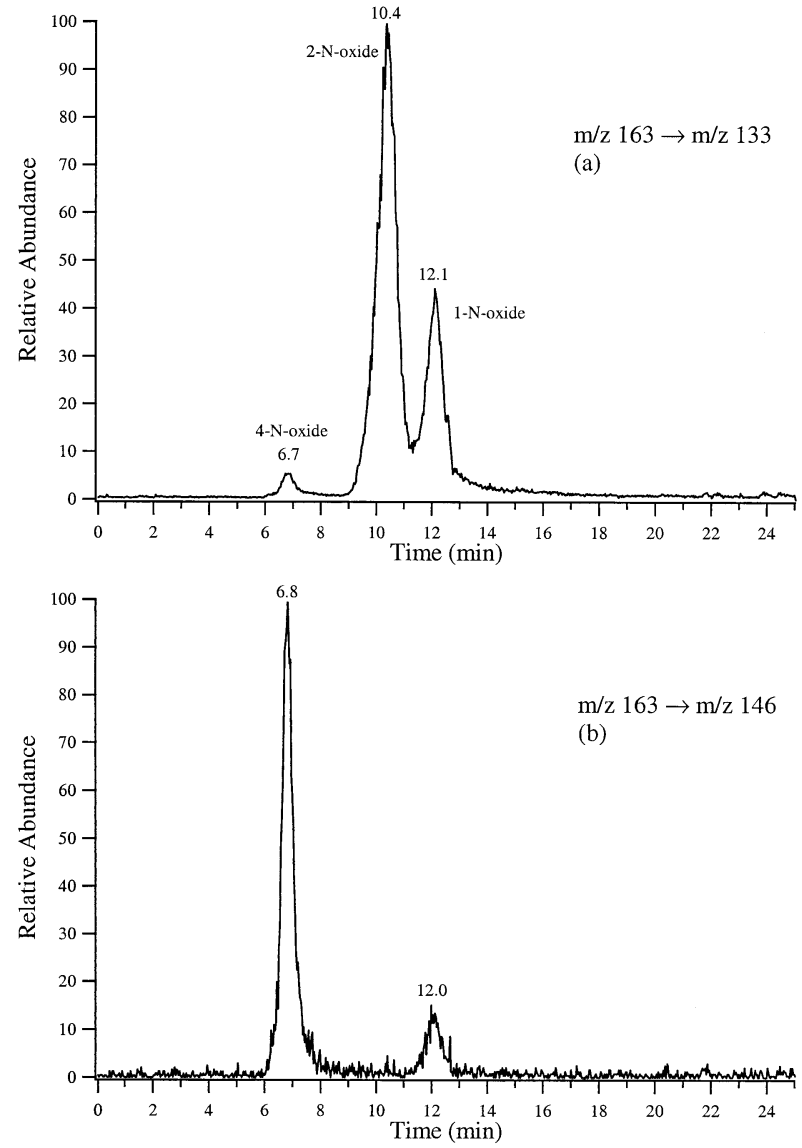

Figure 4. Selected reaction monitoring LC/MS/MS experiments with a mixture of $\mathbf{1}$, its metabolites $(3,4)$ and 3-amino-1,2,4benzotrizine 2-oxide (6). The reactions monitored were (a) $\mathrm{m} / \mathrm{z} 163$ to $\mathrm{m} / \mathrm{z} 133$ and (b) $\mathrm{m} / \mathrm{z} 163$ to $\mathrm{m} / \mathrm{z} 146$.

formed, mobile phases without acetonitrile are recommended for use.

Compounds $\mathbf{1}$ and $\mathbf{3}-\mathbf{5}$ could be easily recognized by their retention times. In real mixtures, the retention times of $\mathbf{1}$ and $\mathbf{4}$ were very close to each other, complicating the detection of 4 in the presence of $\mathbf{1}$ using a UV-detector. Full scan mass spectra, full scan CID mass spectra, and selective reaction monitoring (SRM) were effectively used for detection of tirapazamine and its metabolites. Selective reaction monitoring was very efficient in the recognition of the isomeric monoxides. The best results were achieved when relative intensities of fragment ions at $\mathrm{m} / \mathrm{z} 118, \mathrm{~m} / \mathrm{z} 133$ and $\mathrm{m} / \mathrm{z} 146$ were monitored. The $[\mathrm{m} / \mathrm{z} 118] /[\mathrm{m} / \mathrm{z} 133]$ ion intensity ratios were significantly different for protonated monoxides at any fixed collision energy (Figure 2). No ions at $\mathrm{m} / \mathrm{z}$ 118 were detected for 2 -N-oxide, 6 . Figure 4 shows the results of the LC/MS/MS analysis of an artificial mixture of $1,3,4$, and 6 . In this experiment, selected reactions of ions with $\mathrm{m} / \mathrm{z} 163\left([\mathrm{MH}]^{+}\right)$giving rise to products at $\mathrm{m} / \mathrm{z} 146$ (due to $\mathrm{HO}^{\circ}$ loss) and $\mathrm{m} / \mathrm{z} 133$ (due to $\mathrm{NO}^{\circ}$ loss) were monitored. It should be noted that when LC/MS/MS analyses of the metabolites of tirapazamine were performed, no signals were detected at

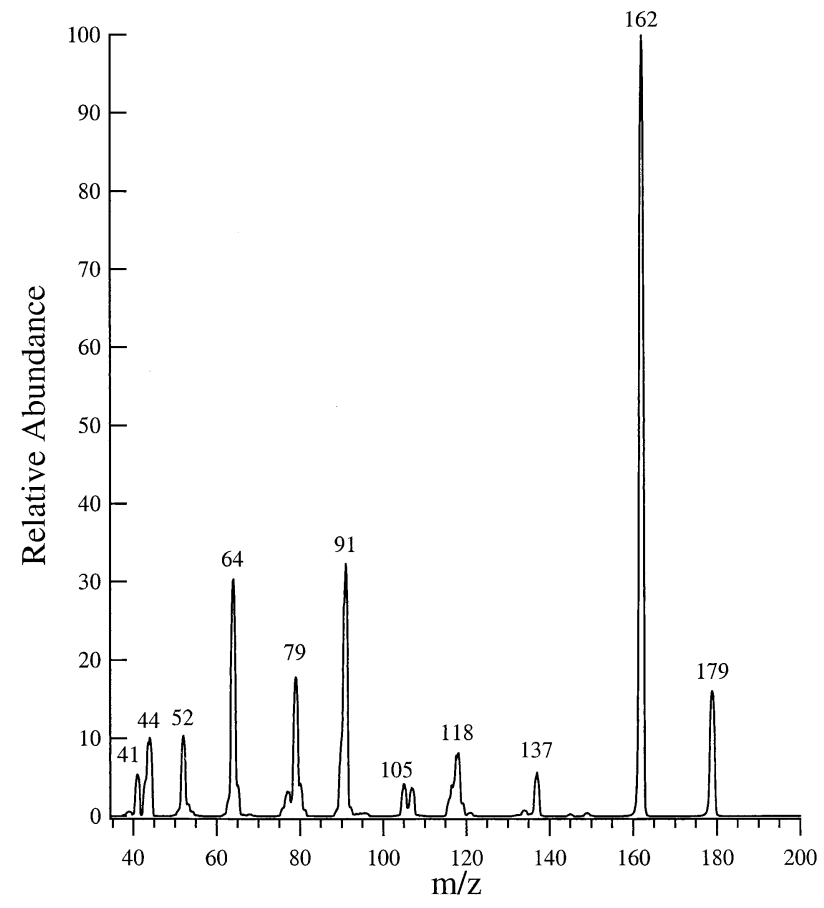

Figure 5. CID mass spectrum of protonated 3-amino-1,2,4-benzotriazine 1,4-dioxide, 1.

retention time corresponding to 2-oxide (6). If this compound had been present in the mixtures, a strong peak at $m / z 133$ would appear in the SRM experiments. The absence of this signal ruled out the formation of 2-oxide upon reductive activation of $\mathbf{1}$, as well as oxygen atom transfer from $1-\mathrm{N}$ or $4-\mathrm{N}$-atoms to the 2-N-atom.

\section{Sites of Protonation for Tirapazamine} and Its Metabolites

In order to gain new fundamental insights regarding the chemical properties of $\mathbf{1}$ and its metabolites and to facilitate interpretation of their mass spectral behavior, we embarked upon a study designed to characterize the preferred sites of protonation in these molecules. As it was stated before, the origin of $[\mathrm{MH}]^{+}$ions did not affect their dissociation characteristics, suggesting that the same site or sites on each molecule was involved in protonated regardless of the ionization method.

Positively charged and neutral products of collisioninduced dissociation of $[\mathrm{MH}]^{+}$ions were analyzed to determine which part of the molecule contained the proton. The presence of an extra hydrogen atom in a neutral product of fragmentation would indicate that this part of the molecule was the initial place for proton attachment. On the other hand, if the ionic product from dissociation carries the proton, it can be concluded that one of the atoms incorporated in the ion was involved in protonation. It is worth noting that collisional activation itself may cause rearrangements of ions, and therefore CID mass spectra may contain peaks corresponding to isomerization of original structures. 
Table 2. Calculated energies for $[\mathbf{I}+\mathrm{H}]^{+}$ions and atomic charges in neutral 1

\begin{tabular}{|c|c|c|c|c|c|c|}
\hline $\begin{array}{l}\text { Protonation } \\
\text { site }\end{array}$ & SCF (A.U.) & $\begin{array}{c}\text { Energy } \\
(\mathrm{Kcal} / \mathrm{mol})^{\mathrm{a}}\end{array}$ & $\begin{array}{c}\text { After zero } \\
\text { point energy } \\
\text { correction }\end{array}$ & $\begin{array}{c}\text { Energy } \\
\text { (Kcal/mol) }\end{array}$ & $\begin{array}{c}\text { Relative } \\
\text { energy } \\
\text { (Kcal/mol) }\end{array}$ & $\begin{array}{l}\text { Atomic } \\
\text { charge }\end{array}$ \\
\hline $1-0$ & -640.038 & -401630.3 & -639.889 & -401536.9 & 4.8 & -0.45 \\
\hline $4-0(2)$ & -640.047 & -401635.7 & -639.897 & -401541.7 & 0.0 & -0.556 \\
\hline $\mathrm{NH}_{2}$ & -640.008 & -401611.3 & -639.857 & -401516.6 & 25.1 & $-0.038^{b}$ \\
\hline $2-N^{2}$ & -640.020 & -401618.9 & -639.871 & -401525.4 & 16.3 & -0.347 \\
\hline
\end{tabular}

a $1 \mathrm{Kcal} / \mathrm{mol}=627.51 \mathrm{~A} . \mathrm{U}$.

${ }^{\mathrm{b}}$ Atomic charge with hydrogen atoms incorporated into $\mathrm{N}$-atom.

The CID mass spectrum of protonated 1 (Figure 5) was dominated by $[\mathbf{1}+\mathrm{H}-\mathrm{OH}]^{+\cdot}$ ions and their dissociation products. The other primary fragmentation product of $[\mathbf{1}+\mathrm{H}]^{+}$was formed by a loss $\mathrm{NCNH}_{2}$. Both of these processes indicate that protonation occurs at one of the oxygen atoms. To find out which oxygen atom was involved in the protonation of $\mathbf{1}$, the CID mass spectrum of $[\mathbf{1}+\mathrm{H}-\mathrm{OH}]^{+\cdot}$ (produced by in-source dissociation) was recorded and compared with CID mass spectra of two possible dissociation products: ionized 3 and 4 . There was a perfect match between the CID mass spectra of $[1+\mathrm{H}-\mathrm{OH}]^{+\cdot}$ and $3^{+}$ions, clearly demonstrating that the oxygen atom in the 4-position of the heterocycle was exclusively lost after protonation. These experimental findings were consistent with quantum chemical calculations of neutral and protonated tirapazamine. The theoretical calculations of neutral 1 [20] showed that the 4-O-atom should possess the highest proton affinity and, therefore, is the most likely site of proton attachment. According to our quantum chemical calculations (Table 2), protonation at the 4-O-atom produced the most stable $[1+\mathrm{H}]^{+}$isomer. The calculated energy of $\mathbf{2}^{+}$ions was lower than that of the molecule with a proton at the 1-O-atom by $\sim 5 \mathrm{kcal} \mathrm{mol}^{-1}$ with the other sites of protonation lying at significantly higher energies (Table 2). The fact that the dissociation characteristics of $[1+$ $\mathrm{H}]^{+}$ions were consistent with exclusive protonation at the oxygen atom in the 4-position of the heterocycle is also supported by the analysis of electron distribution in neutral 1. The negative charge on the 4-O-atom is notably higher than the charge on the 1-O-atom (Table 2 ), which should favour the initial formation of the Structure $2^{+}$. Therefore, experimentally and computa- tionally, there is an overall preference for protonation of the 4-oxygen atom.

The experimental results for protonation of 3-amino1,2,4-benzotriazine and its monoxides were not as straightforward as the data for tirapazamine. The dissociation characteristics of protonated 4-oxide, [4+ $\mathrm{H}]^{+}$, were generally consistent with the proton located at the oxygen atom.

The observation of an ion due to $\mathrm{OH}^{-}$loss can be considered as evidence for proton attachment at the oxygen atom in the 4-position (Structure 8). The presence of a peak due to $\left[\mathrm{MH}-\mathrm{H}_{2} \mathrm{NCN}\right]^{+}$was consistent with the formation of the ion 8. The loss of $\mathrm{H}_{2} \mathrm{NCN}$, however, might well take place from ions having the proton at the 1-N-atom (Structure 9). Also, the ion 9 is the most possible source for the loss of NO. According to our calculations (Table 3 ), the most stable $[4+\mathrm{H}]^{+}$ isomer corresponds to Structure 9. At the same time, charge distributions in neutral 4 indicated that the oxygen atom is the center of the highest electron density. Combined with the experimental results, we can not rule out the possibility of two isomers being produced upon protonation of neutral 4-oxide.<smiles></smiles>

8

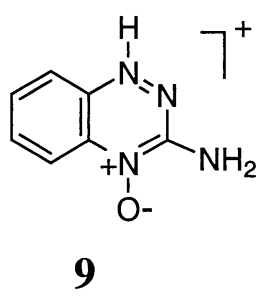

Table 3. Calculated energies for $[4+\mathrm{H}]^{+}$ions and atomic charges in neutral 4

\begin{tabular}{|c|c|c|c|c|c|c|}
\hline $\begin{array}{l}\text { Protonation } \\
\text { site }\end{array}$ & SCF (A.U.) & $\begin{array}{c}\text { Energy } \\
\text { (Kcal/mol) }\end{array}$ & $\begin{array}{l}\text { After zero- } \\
\text { point } \\
\text { energy } \\
\text { correction }\end{array}$ & $\begin{array}{c}\text { Energy } \\
\text { (kcal/mol) }\end{array}$ & $\begin{array}{c}\text { Relative } \\
\text { energy } \\
\text { (kcal/mol) }\end{array}$ & $\begin{array}{l}\text { Atomic } \\
\text { charge }\end{array}$ \\
\hline $4-0(8)$ & -564.862 & -354456.8 & -564.717 & -354366.1 & 7.6 & -0.533 \\
\hline $\mathrm{NH}_{2}$ & -564.824 & -354433.0 & -564.690 & -354348.5 & 25.2 & $-0.042 *$ \\
\hline $1-N(9)$ & -564.876 & -354465.4 & -564.730 & -354373.7 & 0.0 & -0.337 \\
\hline $2-\mathrm{N}$ & -564.865 & -354458.7 & -564.720 & -354367.3 & 6.4 & -0.327 \\
\hline
\end{tabular}

*Atomic charge with hydrogen atoms incorporated into $\mathrm{N}$-atom. 
Table 4. Calculated energies for $[3+\mathrm{H}]^{+}$ions and atomic charges in neutral 3

\begin{tabular}{|c|c|c|c|c|c|c|}
\hline $\begin{array}{l}\text { Protonation } \\
\text { site }\end{array}$ & SCF (A.U.) & $\begin{array}{c}\text { Energy } \\
\text { (Kcal/mol) }\end{array}$ & $\begin{array}{l}\text { After zero- } \\
\text { point energy } \\
\text { correction }\end{array}$ & $\begin{array}{c}\text { Energy } \\
\text { (Kcal/mol) }\end{array}$ & $\begin{array}{c}\text { Relative } \\
\text { energy } \\
\text { (kcal/mol) }\end{array}$ & $\begin{array}{l}\text { Atomic } \\
\text { charge }\end{array}$ \\
\hline $1-0$ & -564.879 & -354467.1 & -564.734 & -354376.0 & 6.9 & -0.438 \\
\hline $4-\mathrm{N}(10)$ & -564.891 & -354474.6 & -564.745 & -354382.9 & 0.0 & -0.573 \\
\hline $\mathrm{NH}_{2}$ & -564.862 & -354456.7 & -564.715 & -354364.2 & 18.7 & $-0.067^{*}$ \\
\hline $2-N(11)$ & -564.877 & -354465.9 & -564.732 & -354374.8 & 8.1 & -0.333 \\
\hline
\end{tabular}

*Atomic charge with hydrogen atoms incorporated into $\mathrm{N}$-atom.

The only dissociation process that would indicate the oxygen atom was a center of protonation of 1-oxide, 3 , is the loss of $\mathrm{N}_{2} \mathrm{OH}$. However, the absence or very low yield of (intermediate) $[\mathrm{M}+\mathrm{H}-\mathrm{OH}]^{+*}$ in the CID mass spectrum, as well as the lack of $\mathrm{N}_{2} \mathrm{OH}^{+}$in the NR mass spectrum of $[3+\mathrm{H}]^{+}$, was incompatible with the presence of a proton at the oxygen atom. The formation of $\left[3+\mathrm{H}-\mathrm{N}_{2} \mathrm{OH}\right]^{+\cdot}$ ions were likely a result of proton attachment to the 2-N-atom. Another possible way to generate $\left[3+\mathrm{H}-\mathrm{N}_{2} \mathrm{OH}\right]^{+\cdot}$ is consecutive loss of $\mathrm{H}^{\cdot}$ and $\mathrm{N}_{2} \mathrm{O}$. This process may take place from ions having a proton at the 4-N-atom. Protonation at either the $2-\mathrm{N}$ or $4-\mathrm{N}$-atoms provides a reasonable explanation for the losses of $\mathrm{NO}$ and $\mathrm{HNCNH}_{2}$. In order to determine the most probable site of protonation, we performed calculations of neutral 3 and four isomeric $[3+\mathrm{H}]^{+}$ions (Table 4). The theory demonstrated that the 4-N-atom should be the centre with the largest negative charge in molecule 3 and the most likely site of the proton attachment. According to the calculation, Structure 10, corresponding to the protonation at the $4-\mathrm{N}$-atom, is the most stable among $[3+\mathrm{H}]^{+}$isomers (Table 4).<smiles></smiles>

10<smiles>C[C+]C[NH+]1NC(N)=Nc2ccccc2[N+]1[O-]</smiles>

11
All ring nitrogen atoms are possible sites of protonation for 3-amino-1,2,4-benzotriazine, 5, based on our calculations (Table 5). The CID mass spectrum of [5 + $\mathrm{H}]^{+}$was dominated by a signal due to $[\mathrm{M}+\mathrm{H}-$
$\left.\mathrm{N}_{2} \mathrm{H}\right]^{+}, m / z$ 118. However, the presence of $[\mathrm{M}+\mathrm{H}-$ $\mathrm{H}]^{+\cdot}$ indicated that the loss of $\mathrm{N}_{2} \mathrm{H}$ which may be the result of consecutive losses of $\mathrm{H}^{*}$ and $\mathrm{N}_{2}$. This process may have taken place from any ring-protonated structure. In addition, a loss of $\mathrm{NH}_{3}$ was observed from [5+ $\mathrm{H}^{+}$, a characteristic process for monosubstituted ammonium ions [21]. For example, this process was the exclusive dissociation pathway that we observed for protonated 2-aminopyridine and 2-aminopyrimidine. This was a minor process in the collision induced dissociation of the protonated 5 , but it is indicative of the involvement of the amino-group in the protonation of 3-amino-1,2,4-benzotriazine.

\section{Neutralization-Reionization Experiments with $\mathrm{M}^{+\cdot}$} and $[\mathrm{M}+\mathrm{H}]^{+}$Ions

One-electron reduction of tirapazamine (1), followed by protonation of the resulting radical anion, yields the neutral radical (2) that is central to the biological activity of the drug $[1,2]$. Neutralization-reionization mass spectrometry (NR MS) [10] is a method allowing the generation of unusual and previously unknown neutrals in the gas phase by neutralization of their (stable) positively charged counterparts. Although the sequence of events leading to activated drug (2) in the NR MS experiment is distinct from those that take place inside cells, this experiment offers a unique method for the generation of the activated form of tirapazamine in the gas phase. These experiments provide a means for examining the unimolecular reactions of 2 under conditions where alternative bimolecular reactions (for example, hydrogen atom abstraction) cannot interfere.

The NR mass spectrum of $[\mathbf{1}+\mathrm{H}]^{+}$, generated by chemical ionization, is shown as Figure 6a. Ammonia was used as a reactant gas to minimize charge exchange

Table 5. Calculated energies for $[\mathbf{V}+\mathrm{H}]^{+}$ions and atomic charges in neutral $\mathbf{5}$

\begin{tabular}{|c|c|c|c|c|c|c|}
\hline $\begin{array}{l}\text { Protonation } \\
\text { site }\end{array}$ & SCF (A.U.) & $\begin{array}{c}\text { Energy } \\
\text { (Kcal/mol) }\end{array}$ & $\begin{array}{l}\text { After zero- } \\
\text { point energy } \\
\text { correction }\end{array}$ & $\begin{array}{l}\text { Energy } \\
\text { (Kcal/mol) }\end{array}$ & $\begin{array}{c}\text { Relative } \\
\text { energy } \\
\text { (kcal/mol) }\end{array}$ & $\begin{array}{l}\text { Atomic } \\
\text { charge }\end{array}$ \\
\hline $4-N(12)$ & -489.705 & -307294.6 & -489.563 & -307205.9 & 4.6 & -0.554 \\
\hline $\mathrm{NH}_{2}$ & -489.681 & -307279.5 & -489.538 & -307190.2 & 10.3 & $-0.065^{*}$ \\
\hline $1-N$ & -489.695 & -307288.3 & -489.567 & -307208.4 & 2.1 & -0.311 \\
\hline $2-\mathrm{N}$ & -489.712 & -307299.3 & -489.571 & -307210.5 & 0.0 & -0.301 \\
\hline
\end{tabular}

*Atomic charge with hydrogen atoms incorporated into $\mathrm{N}$-atom. 


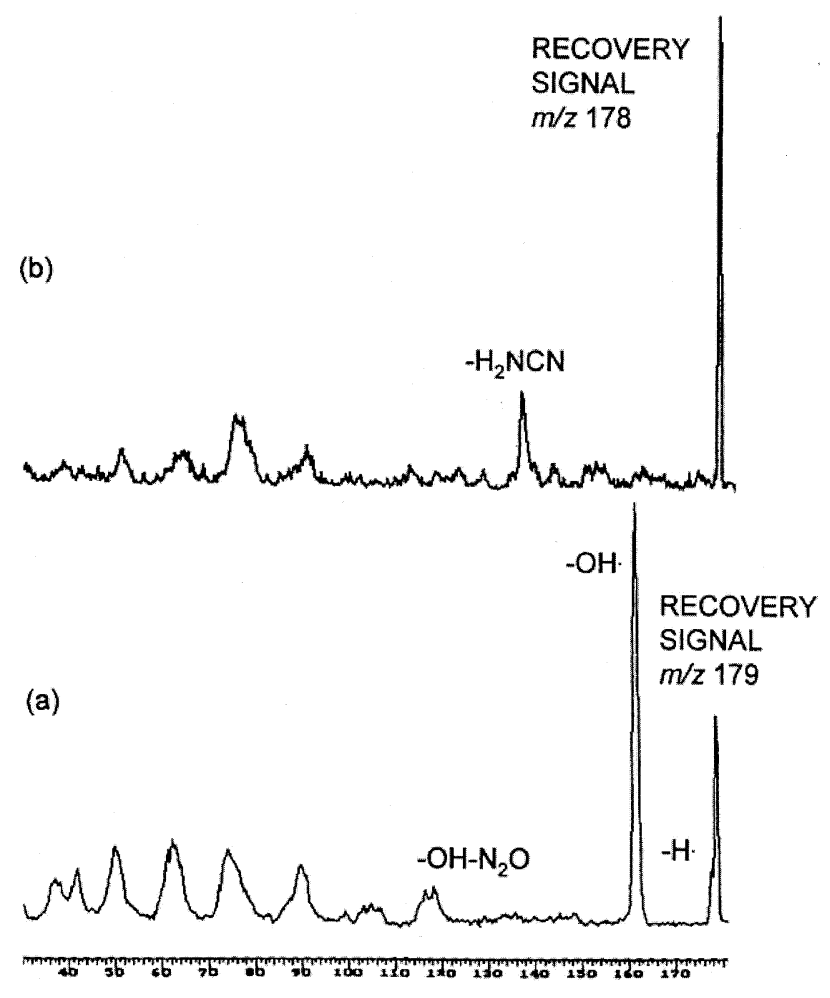

Figure 6. Neutralization-reionization mass spectra of $[\mathrm{I}+\mathrm{H}]^{+}$, $m / z 179$ ions (a) and $\mathbf{1}^{+*}, m / z 178$ ions (b).

processes. (Abundant molecular ion signals were observed when using iso-butane for $\mathrm{CI}$.) By using $\mathrm{NH}_{3}$ for $\mathrm{CI}$, the $\left[\mathrm{M}^{+}\right] /[\mathrm{M}+\mathrm{H}]^{+}$peak intensity ratio was reduced to less than 0.08 . As a result, at least $99 \%$ of the ions with $\mathrm{m} / \mathrm{z} 179$ corresponded to $[\mathbf{1}+\mathrm{H}]^{+}$ions, whereas the contribution of isotopic $\mathbf{1}^{+\cdot}$ ions was negligible $(\leq 1 \%)$. Our measurements showed that neutralization-reionization efficiencies of $\mathbf{1}^{+\cdot}$ and $[\mathbf{1}+\mathrm{H}]^{+}$ions were similar at 0.01 and $0.02 \%$, respectively. The efficiencies were measured as the relative intensities of recovery peaks to the main ion beam before the NR event. This result indicated that the NR mass spectrum of ions with $\mathrm{m} / \mathrm{z} 179$ indeed corresponded to $[\mathbf{1 H}]^{+}$. Additional support for this conclusion can be obtained by comparison of NR mass spectra of $[\mathbf{1}+\mathrm{H}]^{+}(\mathrm{m} / \mathrm{z}$ 179) and $\mathbf{1}^{+*}(\mathrm{~m} / \mathrm{z}$ 178) ions (Figure 6). The major fragment ion in the latter is formed by a loss of $\mathrm{H}_{2} \mathrm{NCN}$. This product was not found in the NR mass spectrum of [1 + $\mathrm{H}]^{+}$ions, confirming its high isotopic purity.

Three important peaks were observed in the NR mass spectrum of protonated tirapazamine. The peak at $\mathrm{m} / \mathrm{z} 179$ corresponded to reionized 2. The peaks observed at $\mathrm{m} / \mathrm{z} 178$ and 162 originated from losses of $\mathrm{H}$ and $\mathrm{OH}$, respectively. The observation of the recovery signal at $\mathrm{m} / \mathrm{z} 179$ demonstrated that the neutral analogue of protonated tirapazamine ( 2 on Scheme 1 ) is indeed a stable species in the gas phase with a life-time of at least $5 \mu \mathrm{s}$.

NR MS experiments with $\left[\mathbf{1}+\mathrm{NH}_{4}\right]^{+}$ions were performed to confirm that neutral 2 could be generated in the gas phase. An advantage of using $\left[1+\mathrm{NH}_{4}\right]^{+}$ ions was that they were free of interference from any other ions. A recovery signal, corresponding to $[\mathbf{1}+$ $\left.\mathrm{NH}_{4}\right]^{\prime}$ neutrals, was not detected. The instability of these species can be explained by a low binding energy of ammonia or by large differences in geometry between the ions and the corresponding neutrals. The general instability of neutral analogues of proton-bound dimers under NR MS conditions has been reported on many occasions. [Stable neutral anologues of proton-bound dimers can be generated by using neutralization targets with very low ionization energies and by excluding the reionization step. For example, ion beam experiments resulted in stable $\left(\mathrm{NH}_{3}\right)_{\mathrm{n}} \mathrm{H}^{\circ}$ clusters] [22]. Therefore, the lack of production of stable $\left[1 . . \mathrm{H} . . \mathrm{NH}_{3}\right]$ radicals was in agreement with this tendency. The highest mass peak $\left(\mathrm{m} / \mathrm{z}\right.$ 179) in the NR mass spectrum of $\left[\mathbf{1}+\mathrm{NH}_{4}\right]^{+}$ corresponded to reionized $1 \mathrm{H}$, providing direct evidence for the stability of the latter within the mass spectral time frame. Our quantum chemical calculations were consistent with these results. The radical 2 was found to be a stable species. Two sets of calculations were performed (Table 6). In the first, the geometry of neutral $\mathbf{1}$ was used and an $\mathrm{H}$-atom was added to the 4-O-atom. In the second calculation, the geometry of the cation 2 was the starting point for the optimization of the corresponding radical. The second procedure used unrestricted geometry optimization. The energies of the radicals calculated by the two methods differed by $\sim 12$ kcal $\mathrm{mol}^{-1}$, but their intrinsic stability was demonstrated.

The NR mass spectra of $\left[\mathbf{1}+\mathrm{NH}_{4}\right]^{+}$and $[\mathbf{1}+\mathrm{H}]^{+}$ ions displayed abundant ions at $\mathrm{m} / \mathrm{z} 162$. Their appearance in the NR mass spectrum can be accounted by two processes: (1) Loss of $\mathrm{OH}$ from neutral $1 \mathrm{H}^{*}$ prior to reionization, or (2) reionization of $1 \mathrm{H}^{-}$followed by dissociation of $[\mathbf{1}+\mathrm{H}]^{+}$ions with a loss of $\mathrm{OH}^{-}$radical. The $[1+\mathrm{H}-\mathrm{OH}]^{+*} /[\mathbf{1}+\mathrm{H}]^{+}$ion peak ratio in the NR mass spectrum of $\left[\mathbf{1}+\mathrm{NH}_{4}\right]^{+}$ions $(<0.5)$ was significantly lower than the same ratio in the NR experiments

Table 6. Calculated energies of neutral analogues of protonated 1, 4 and 5

\begin{tabular}{|c|c|c|c|c|}
\hline \multirow{2}{*}{$\begin{array}{l}\text { Structure of } \\
\text { a neutral }\end{array}$} & \multicolumn{2}{|c|}{ Geometry of a neutral compound $+\mathrm{H}$} & \multicolumn{2}{|c|}{ Unrestricted optimization of geometry } \\
\hline & Energy (A.U.) & Energy (kcal/mol) & Energy (A.U.) & Energy $(\mathrm{kcal} / \mathrm{mol})$ \\
\hline 2 & -636.500 & -399410.5 & -636.518 & -399421.4 \\
\hline 10 & -561.710 & -352478.5 & \multicolumn{2}{|c|}{ Convergence failure } \\
\hline 11 & -561.712 & -352480.1 & -561.726 & -352488.8 \\
\hline 12 & -486.899 & -305533.8 & -486.920 & -305547.2 \\
\hline
\end{tabular}




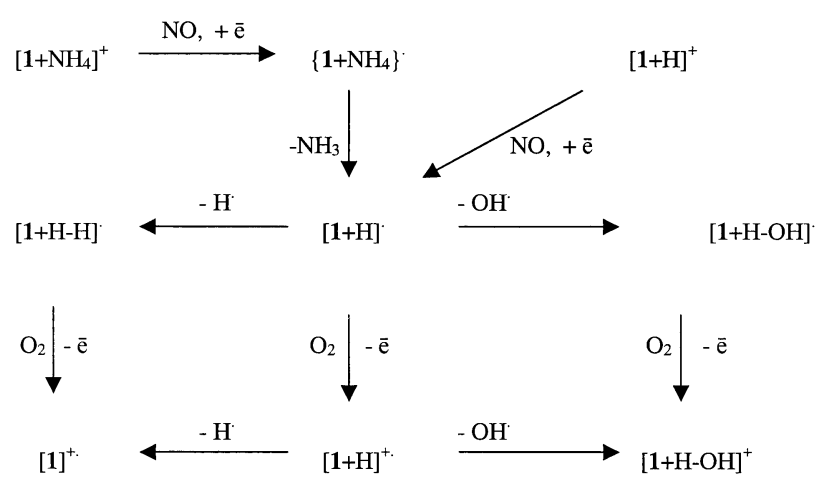

Scheme 2. Transformations of $\left[\mathbf{1}+\mathrm{NH}_{4}\right]^{+}$and $[\mathbf{1}+\mathrm{H}]^{+}$ions and neutrals in neutralization-reionization conditions.

with $[\mathbf{1}+\mathrm{H}]^{+}$ions $(\sim 3)$. The different ion peak ratios is most likely due to a difference in internal energies during the formation of $1 \mathrm{H}$. In the case of the ammonium adduct, it can be assumed that the loss of $\mathrm{NH}_{3}$ took place upon neutralization and all "recovery" $[\mathbf{1}+$ $\mathrm{H}]^{+}$ions were produced by reionization of the corresponding radicals.

Similar arguments can be applied to the formation of $[\mathbf{1}+\mathrm{H}-\mathrm{H}]^{+\cdot}$ ions in the NR mass spectra of $[\mathbf{1}+$ $\left.\mathrm{NH}_{4}\right]^{+}$and $[\mathbf{1}+\mathrm{H}]^{+}$ions. Higher abundance of $[\mathrm{M}+\mathrm{H}$ $-\mathrm{H}]^{+\cdot}$ ions in the NR mass spectrum of the latter can be rationalized by the increased dissociation of $[1+\mathrm{H}]^{\circ}$ neutrals generated from $[1+\mathrm{H}]^{+}$ions compared to the same neutrals produced by neutralization of the ammonium adduct $\left[\mathbf{1}+\mathrm{NH}_{4}\right]^{+}$.

The results of the NR MS study of $\left[\mathbf{1}+\mathrm{NH}_{4}\right]^{+}$and $[1+\mathrm{H}]^{+}$ions are summarized in Scheme 2. Two important conclusions can be drawn. First, the neutral analogue of protonated tirapazamine is a stable species in the gas phase, consistent with the notion that it could form in neutral, aqueous solution (Scheme 1). Protonation of tirapazamine occurred at the oxygen atom bound to the $4-\mathrm{N}$-atom. Secondly, $[\mathbf{1}+\mathrm{H}]$ radicals can readily lose hydroxyl radical. An estimate of the dissociation energy can be obtained using a half-life of $5 \mu \mathrm{s}$ for a unimolecular reaction. The estimated dissociation energy is $14 \mathrm{kcal} \mathrm{mol}^{-1}$. These results provide a reasonable value for the activation energy of the process which is proposed as a part of the metabolic transformation of tirapazamine in the condensed phase (Scheme 1).

NR MS experiments were also performed on ionized 3 and $\mathbf{5}$ and their protonated counterparts. In all cases, survivor ions dominated the NR mass spectra. The observation of strong recovery signals in the NR mass spectra of $[3+\mathrm{H}]^{+}$and $[5+\mathrm{H}]^{+}$ions (Figure 7) demonstrated the intrinsic stability of the corresponding $\mathrm{MH}^{-}$neutrals. The NR mass spectra were similar to the CID mass spectra of the corresponding ions, indicating that the ions surviving neutralization-reionization retained the atom connectivity of the ions prior to the NR event. It is known [13, 23, 24] that neutral analogues of ammonium ions are metastable and therefore, if protonation of $\mathbf{3}$ or $\mathbf{5}$ involved the amino group,

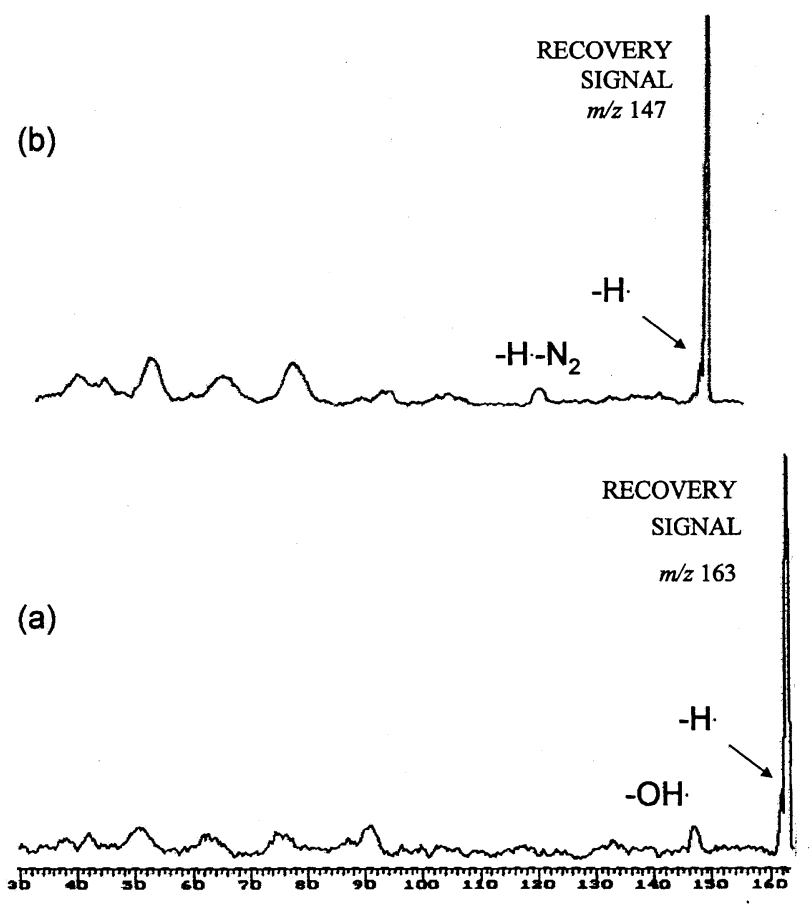

Figure 7. Neutralization-reionization mass spectra of $[3+\mathrm{H}]^{+}$ (a) and $[5+\mathrm{H}]^{+}$ions (b).

their neutralization would result in unstable neutrals. The presence of $[\mathrm{MH}-17]^{+}$ions in the NR mass spectrum of $[3+\mathrm{H}]^{+}$ions may be why the ions entering the NR event are those with a proton at the amino group that do not survive, while protonation at the oxygen atom resulted in a possible source for stable [3 $+\mathrm{H}]$ neutrals. By analogy with nitrogen-containing heterocyclic systems studied previously [23], and based on this experimental and theoretical work, ring- $\mathrm{N}$-atom protonated species are the most likely candidates for surviving neutralization-reionization. Neutral analogues of ions $11([3+\mathrm{H}])$ and $\mathbf{1 2}([5+\mathrm{H}])$ were calculated to be stable radicals (Table 6).

\section{Conclusions}

In the present work, the dissociation characteristics of ionized and protonated 3-amino-1,2,4-benzotriazine and its mono- and di-oxides were analyzed to correlate their structure and reactivity in the gas phase. Fragmentation pathways of protonated tirapazamine and its metabolites yield an insight to the site(s) of protonation of these molecules. The oxygen atom at the 4-position of the heterocycle was the exclusive site of protonation of 1 and a preferable place of proton attachment of 4-oxide, 4. Quantum chemical calculations showed that the 4-O-atom of $\mathbf{1}$ to be the site with the highest negative charge, consistent with experimental observations. In addition, 2 ions with a proton at the 4-O-atom were calculated to be the most stable isomer of protonated tirapazamine. The calculations also predicted reasonable stability for 8 , although the most stable $[4+\mathrm{H}]^{+}$ isomer corresponded to protonation at the $1-\mathrm{N}$-atom. 
Quantum chemical calculations identified the ring $\mathrm{N}$-atoms to be the most probable sites for protonation for 3 and 5. These results were generally consistent with most of the fragmentation pathways of $[3+\mathrm{H}]^{+}$and $[5$ $+\mathrm{H}]^{+}$ions. However, some dissociation characteristics of these ions indicated the involvement of other groups, e.g., the amino-group in 5 and 1-O-atom in 3.

The differences in the dissociation of $[\mathrm{M}+\mathrm{H}]^{+}$ions of the isomeric monoxides allowed their identification using MS/MS techniques. Methods of mixture separation were developed for tirapazamine and its metabolites. LC/MS/MS experiments employing either ESI or APCI ionization techniques enabled identification of the various mixture components.

An important goal of this work was to investigate the validity of the proposed mechanism (Scheme 1) for the metabolic transformations of tirapazamine. Our work provides the first direct observation of the neutral radical 2, which has been proposed key intermediate in the metabolic activation of tirapazamine. There was no direct evidence for the formation of this radical prior to our experiments. The present work provides the first preparation of this species in the gas phase in its pure form. The intrinsic stability of neutral 2 was shown by the observation of a recovery signal in the NR mass spectrum of $[\mathbf{1}+\mathrm{H}]^{+}$ions. All mass spectral characteristics of the latter were consistent with tirapazamine exclusively protonated at the 4-O-atom tirapazamine. The life-time of $\mathbf{2}$ in the gas phase exceeded at least $5 \mu \mathrm{s}$. Partial dissociation of neutral 2 with a loss of $\mathrm{OH}^{-}$took place during the course of the NR MS event. This constitutes the first direct evidence that the activated form of tirapazamine can undergo unimolecular fragmentation to release hydroxyl radical. The activation energy for this process was estimated to be $\sim 14 \mathrm{kcal}$ $\mathrm{mol}^{-1}$. This low energy barrier provides the first evidence that the previously proposed loss of hydroxyl radical from activated tirapazamine is an energetically feasible reaction (Scheme 1).

Several other previously unknown neutrals were generated using the NR MS technique. Neutral counterparts of protonated $\mathbf{3}$ and $\mathbf{5}$ were obtained as stable gas phase species with a minimum life time of $3 \mu \mathrm{s}$. Their structure(s) were assigned to radicals having an extra hydrogen atom at one of the ring $\mathrm{N}$-atoms of the corresponding molecules.

\section{Acknowledgments}

The authors thank the University of Missouri Research Board for support of this research and A.A. Mommers for modification of the ZAB-SE mass spectrometer for neutralization-reionization studies. DZ thanks Professor H. Budzikiewich for help in literature search.

\section{References}

1. Brown, J. M. The Hypoxic Cell: A Target for Selective Cancer Therapy-Eighteenth Bruce F. Cain Memorial Award Lecture. Cancer Res. 1999, 59, 5863-5870.
2. Denny, W. A.; Wilson, W. R. Tirapazamine: A Bioreductive Anticancer Drug that Exploits Tumour Hypoxia. Expert Opin. Investig. Drugs 2000, 9, 2889-2901.

3. Laderoute, K.; Wardman, P.; Rauth, A. M. Molecular Mechanisms for the Hypoxia-Dependent Activation of 3-Amino1,2,4-Benzotriazine-1,4-Dioxide (SR 4233). Biochem. Pharmacol. 1988, 37, 1487-1495.

4. Wardman, P.; Priyadarsini, K. I.; Dennis, M. F.; Everett, S. A.; Naylor, M. A.; Patel, K. B.; Stratford, I. J.; Stratford, M. R. L.; Tracy, M. Chemical Properties Which Control Selectivity and Efficacy of Aromatic N-Oxide Bioreactive Drugs. Brit. J. Cancer Suppl. 1996, 74, S70-S74.

5. Priyadarsini, K. I.; Tracy, M.; Wardman, P. The One-Electron Reduction Potential of 3-Amino-1,2,4-Benzotriazine 1,4-Dioxide (Tirapazamine): A Hypoxia-Selective Bioreactive Drug. Free Rad. Res. 1996, 25, 393-399.

6. Daniels, J. S.; Gates, K. S. DNA Cleavage by the Antitumor Agent 3-Amino-1,2,4-Benzotriazine 1,4-Dioxide (SR4233): Evidence for Involvement of Hydroxyl Radical. J. Am. Chem. Soc. 1996, 118, 3380-3385.

7. Jones, G. D. D.; Weinfeld, M. Dual Action of Tirapazamine in the Induction of DNA Strand Breaks. Cancer Res. 1996, 56, 1584-1590.

8. Daniels, J. S.; Gates, K. S.; Tronche, C.; Greenberg, M. M. Direct Evidence for Bimodal DNA Damage Induced by Tirapazamine. Chem. Res. Toxicol. 1998, 11, 1254-1257.

9. Hwang, J.-T.; Greenberg, M. M.; Fuchs, T.; Gates, K. S. Reaction of the Hypoxia-Selective Antitumor Agent Tirapazamine with a C1'-Radical in Single-Stranded and DoubleStranded DNA: The Drug and Its Metabolites Can Serve as Surrogates for Molecular Oxygen in Radical-Mediated DNA Damage Reactions. Biochemistry 1999, 38, 14248-14255.

10. Siim, B. G.; Van Zijl, P. L.; Brown, J. M. Tirapazamine-Induced DNA Damage Measured Using the Comet Assay Correlates with Cytotoxicity Towards Hypoxic Tumor Cells in Vitro. Brit. J. Cancer 1996, 73, 952-960.

11. Fitzsimmons, S. A.; Lewis, A. D.; Riley, R. J.; Workman, P. Reduction of 3-Amino-1,2,4-Benzotriazine-1,4-di-N-Oxide (Tirapazamine, WIN 59075, SR 4233) to a DNA-Damaging Species: A Direct Role for NADPH:Cytochrome P450 Oxidoreductase. Carcinogenesis 1994, 15, 1503-1510.

12. McLafferty, F. W. Studies of Unusual Simple Molecules by Neutralization-Reionization Mass Spectrometry. Science 1990, 247, 925-929.

13. Wesdemiotis, C. Neutralization-Reionization in Mass Spectrometry. Encyclopedia of Spectroscopy and Spectrometry; In: Lindon, G. C.; Tranter, G. E.; Holmes, J. L., Eds.; Academic Press: New York, 1999; pp. 1469-1479.

14. Fuchs, T.; Chowdhury, G.; Barnes, C. L.; Gates, K. S. 3-Amino1,2,4-benzotriazine 4-Oxide: Characterization of a New Metabolite Arising from Bioreductive Processing of the Antitumor Agent 3-Amino-1,2,4-Benzotriazine 1,4-Dioxide (Tirapazamine). J. Org. Chem. 2001, 66, 107-114.

15. Frisch, M. J.; Trucks, G. W.; Schlegel, H. B.; Scuseria, G. E.; Robb, M. A.; Cheeseman, J. R.; Zakrzewski, V. G.; Montgomery, J. A., Jr.;; Stratmann, R. E.; Burant, J. C.; Dapprich, S.; Millam, J. M.; Daniels, A. D.; Kudin, K. N.; Strain, M. C.; Farkas, O.; Tomasi, J.; Barone, V.; Cossi, M.; Cammi, R.; Mennucci, B.; Pomelli, C.; Adamo, C.; Clifford, S.; Ochterski, J.; Petersson, G. A.; Ayala, P. Y.; Cui, Q.; Morokuma, K.; Malick, D. K.; Rabuck, A. D.; Raghavachari, K.; Foresman, J. B.; Cioslowski, J.; Ortiz, J. V.; Stefanov, B. B.; Liu, G.; Liashenko, A.; Piskorz, P.; Komaromi, I.; Gomperts, R.; Martin, R. L.; Fox, D. J.; Keith, T.; Al-Laham, M. A.; Peng, C. Y.; Nanayakkara, A.; Gonzalez, C.; Challacombe, M.; Gill, P. M. W.; Johnson, B. G.; Chen, W.; Wong, M. W.; Andres, J. L.; Head-Gordon, M.; 
Replogle, E. S.; Pople, J. A. Gaussian 98, Rev A.7. Gaussian, Inc.: Pittsburgh, 1998.

16. Becke, A. D. Density-functional thermochemistry. III. The role of exact exchange. J. Chem. Phys. 1993, 98, 5648-5652.

17. Lee, C.; Yang, W.; Parr, R. G. Development of the ColleSalvetti Correlation-Energy Formula into a Functional of the Electron Density. Phys. Rev. B Condensed Matter 1988, 37, 785-789.

18. Porter, Q. N. Mass Spectrometry of Heterocyclic Compounds; 2nd ed. Wiley, 1985.

19. Wulfson, N. S.; Zaikin, V. G.; Mikaia, A. I. Mass Spectrometry of Organic Compounds. Khimia: Moscow, 1986; p 139.

20. Ban, F.; Gauld, J. W.; Boyd, R. J. Modeling the Action of an Antitumor Drug: A Density Functional Theory Study of the
Mechanism of Tirapazamine. J. Am. Chem. Soc. 2001, 123 $7320-7325$.

21. Harrison, A. G. Chemical Ionization Mass Spectrometry; 2nd ed. CRC Press: Boca Raton, 1992.

22. Gellene, G. I.; Porter, R. F. An Experimental Study of Hypervalent Molecular Clusters by Neutralized Ion Beam Spectroscopy: Ammonium-Ammonia $\left(\mathrm{NH}_{4}\left(\mathrm{NH}_{3}\right)_{\mathrm{n}}\right)$ and Deuterated Ammonium-Ammonia $\left(\mathrm{ND}_{4}\left(\mathrm{ND}_{3}\right)_{\mathrm{n}}\right)$. J. Phys. Chem. 1985, 88, $6680-6684$.

23. Turecek, F. Modeling Nucleobase Radicals in Mass Spectrometer,. J. Mass Spectrom. 1998, 33, 779-795.

24. Nguyen, V. Q.; Sadilek, M.; Ferrier, J.; Frank, A. J.; Turecek, F. Metastable States of Dimethylammonium, $\left(\mathrm{CH}_{3}\right)_{2} \mathrm{NH}_{2}$. J. Phys. Chem A. 1997, 101, 3789-3799. 